\title{
The Two Sides of Covid-19 in Kenya: Getting A Closer Look
}

\author{
Julius M. Huho \\ Department of Arts and Social Sciences, Garissa University \\ DOI: 10.29322/IJSRP.10.08.2020.p10459 \\ http://dx.doi.org/10.29322/IJSRP.10.08.2020.p10459
}

\begin{abstract}
Coronavirus Disease (COVID-19) is an infectious respiratory disease which was first reported in Wuhan, China in December, 2019 and later spread to other countries. The alarming levels of spread and severity of the disease made the World Health Organization (WHO) declare the outbreak a global pandemic on March 11, 2020. By July 8, 2020, the disease had claimed 548,207 lives globally. The pandemic caused grief and suffering as the number of deaths increased every day. Kenya not being an exception, the government put up some measures in the attempt to contain the spread of the disease. These measures led to unprecedented challenges which included loss of livelihoods, disruption of the school calendar and human mortality through police brutality. On the other hand, as the country continues to contain the disease, several opportunities emerged. Such opportunities ranged from enhanced innovation to improved health facilities and personal hygiene. This paper, therefore, highlights on these two sides of COVID-19 in Kenya and the lessons learnt.
\end{abstract}

Index Terms- COVID-19, containment measures, Kenya, pandemic, socioeconomic

\section{INTRODUCTION}

$\mathrm{C}$ oronavirus Disease (COVID-19) is an infectious respiratory disease caused by a new strain of coronavirus. The first case of the disease was reported in Wuhan, China but later spread to 216 countries, areas or territories by July 8th 2020 . It spreads by respiratory droplets released when someone with the virus coughs, sneezes or talks and the droplets inhaled or land in the mouth or nose of a person close by [1]. Thus, spread easily among people who are in close contact of about 2 meters. The disease, which majorly manifests itself through high fever, dry cough and tiredness, was declared a pandemic by the World Health Organization (WHO) in March 2020. As of July 8th 2020, data from Worldometer [2] indicated that over 12 million people had contracted the disease. Of the infected, 6,953,556 had recovered while 548,207 had succumbed to COVID-19 related complications.

The first case of Coronavirus Disease (COVID-19) in Kenya was reported on 13th March 2020. And as of July 6th 2020, out of 191,394 samples tested, 8067 people were confirmed positive of the COVID-19 out of which 164 had succumbed to the disease and 2,414 had recovered. Of the confirmed positive cases, about $88 \%$ were through local transmissions while $12 \%$ were from other nationalities or Kenyan citizens who had previously travelled to countries affected with the disease. The steady rise in the number of new infections saw the government of Kenya impose some containment measures in a phased manner depending on the magnitude of the disease. Overall, the containment measures included dawn to dusk curfew (5 am $-7 \mathrm{pm}$ ), cessation of movement in and out of Nairobi, Mombasa and Mandera, wearing of face masks, closing of all learning institutions and public gatherings including places of worship. Other measures included reduction of the carrying capacity of public vehicles to $60 \%$, ban of public air transport, ban of handshaking and mandatory installation of handwashing stands in all public places and regular hand washing or sanitizing. These measures precipitated myriad of socioeconomic challenges on one hand and some opportunities on the other. This paper highlights on the two sides of COVID-19 in Kenya.

\section{METHODOLOGY}

Mixed methods were used in obtaining data for this study. The methods used included: telephone and face-to-face interviews and literature review. The study was domiciled in Kenya.

\section{THE SOCIOECONOMIC CHALLENGES OF COVID-19}

\section{A. Domestic Violence}

With schools closed, 7 pm - 5 am curfew imposed, stay home orders and some employees sent home, the pandemic brought an environment of confinement, uncertainty, heightened levels of stress combined with the financial hardships. A study undertaken by the Ministry of Health and Population Council in April, 2020 revealed that $39 \%$ of women and $32 \%$ of men were experiencing tensions in their homes [3]. This stressful environment bred cases of domestic and sexual violence as well as violence against children in some families. Besides, removing children from a protective school environment heightened these risks. The National Council on Administration of Justice observed a sharp rise in sexual offences during the COVID-19 pandemic. Among all the crimes committed since COVID-19 was reported in Kenya, sexually related violence ranked third. A report by [4] indicates 
that in the first three weeks of dusk to dawn curfew the number of calls regarding domestic violence increased by $34 \%$ (Figure 1 ).

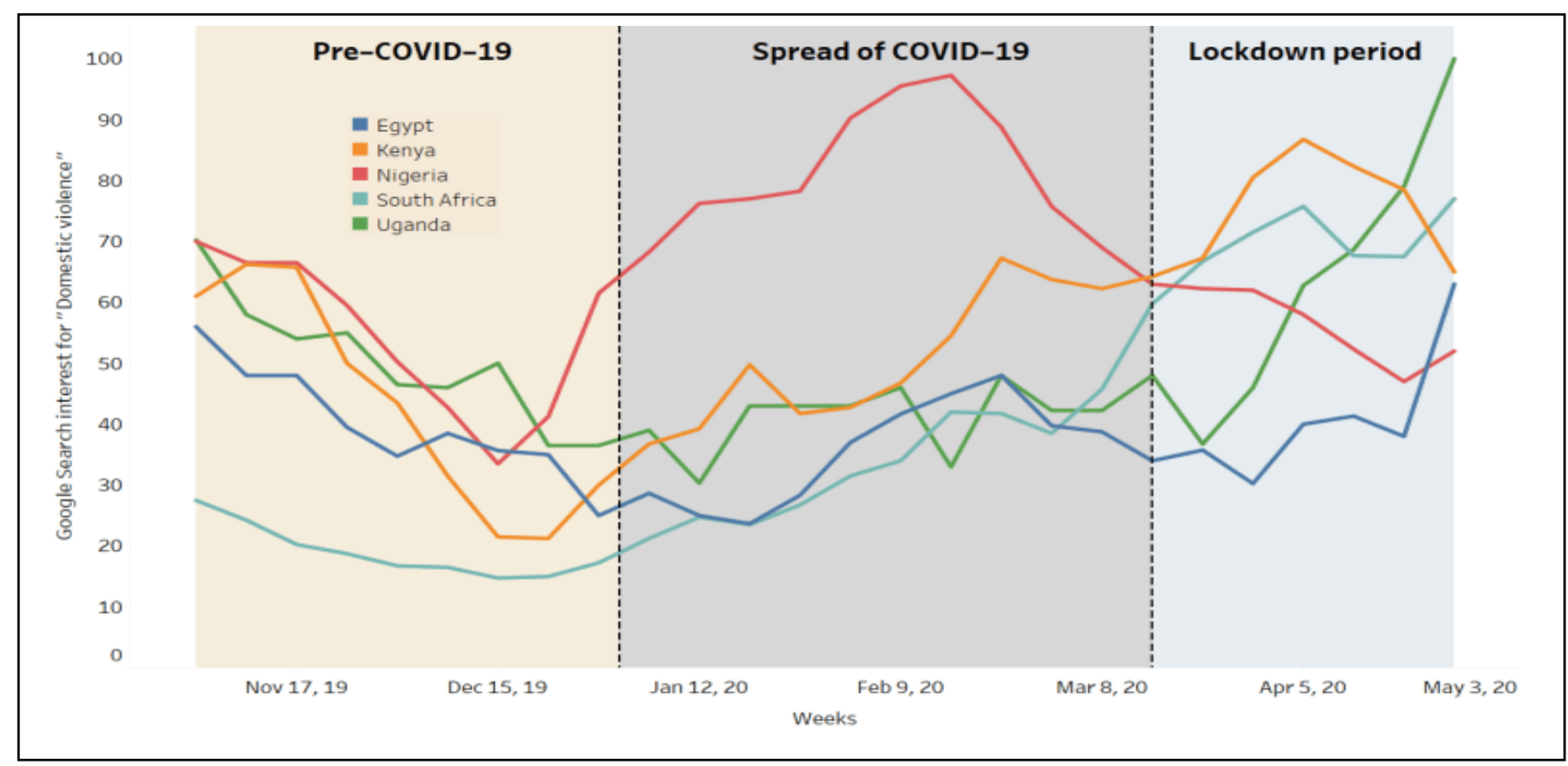

Figure 1: Domestic violence trends in different countries [5]

\section{B. Financial Hardships}

The economic hardships caused by the pandemic have caused treasury to set the economic growth rate to $2.5 \%$ from a previous forecast of 5.4 and is expected to decline to $1.0 \%$ if the impacts of COVID-19 on economic activities last longer. This will be occasioned by the anticipated $20 \%$ decline in tourism activities, $3.1 \%$ decline in total import value, $50 \%$ reductions in household and business spending, 30\% disruption in the supply chain for key inputs in machinery and chemicals and a US\$ $658 \mathrm{~m}$ deficit in revenue collection in April, May and June 2020 [4]. In the endeavour to cushion the country against the negative economic effects of COVID-19, the government imposed some tax interventions measures. The measures included a $100 \%$ tax relief for low-income-earning persons, a reduction in Pay-As-You-Earn (PAYE) rate from $30 \%$ to $25 \%$ for others, lower VAT and a corporate tax cut.

Most of the people employed in tourism and hospitality sector (which contributes to $8.5 \%$ of the total employment in Kenya) lost jobs or risked losing their jobs due to closure of hotels and shutdown of global aviation. For example, the Safari Hotel in Maasai Mara National Park sacked its employees. In the flower sector, about 30,000 temporary workers had been laid off and another 40,000 permanent staff sent on unpaid leave. The sector was losing approximately US\$ 2.5 million per day and had recorded more than $50 \%$ drop in exports. A survey by the Kenya National Bureau of Statistics (KNBS) in May 2020 revealed a decline in labour participation from 75\% in 2019 to $56.8 \%$ in April 2020. In the transport sector, vehicles reduced their carrying capacity to $60 \%$ with buses plying in and out of Nairobi, Mombasa and Mandera
Counties halting their services due to lockdown in these counties. The suspension of international flights resulted in airlines sending home most of its workers on unpaid leave and pay cuts for the management team. These measures on transport led to a $51.7 \%$ increase in transport cost nationally forcing $32.2 \%$ of Kenyans to opt for walking where possible. These led to loss of livelihoods or reduced income both to service providers and owners of the vehicles. A survey by KNBS in May 2020 indicated that the population in active employment (both in formal and informal) declined from $77.6 \%$ to $65.3 \%$ and from $65.3 \%$ to $48.8 \%$ for men and women respectively [6]. Between March and May 2020, the effects of the pandemic had rendered about 133,657 Kenyans jobless.

\section{Disruption of School Calendar}

As one of the COVID-19 containment measure, all learning institutions in Kenya were closed on 15th March 2020. With the rising new cases of COVID-19 infections, the government proposed January 2021 as the tentative date of opening schools for basic education (primary and secondary schools). Thus, the year 2020 was declared a "lost academic year" due to COVID-19. Together with this, terminal examinations for primary school (the Kenya Primary Certificate Examinations) and secondary school (the Kenya Certificate of Secondary Examimations) were postponed to later date in 2021. For intermediate and tertiary education, a phased reopening was to commence in September 2020 after the institutions meet the laid down containment measures by the ministry of health. 


\section{Police Brutality}

In enforcing the dusk to dawn curfew as a COVID-19 containment measure, the police used excessive force on non-compliant citizens (Figure 2). Report from IPOA of June 2nd 2020 indicated that police actions during the curfew enforcement resulted in 15 deaths and 31 serious injuries. Also, there were 87 reported complaints against police since the end of March. Some of the deaths attributed to police actions included that of a 13-years old who was shot by police while on their house balcony after the curfew began and a homeless man from the Mathare slums alleged to have violated the curfew hours. The killings in Mathare led to public demonstration. The demonstrators argued that police brutality had led to more deaths than the COVID-19 itself.

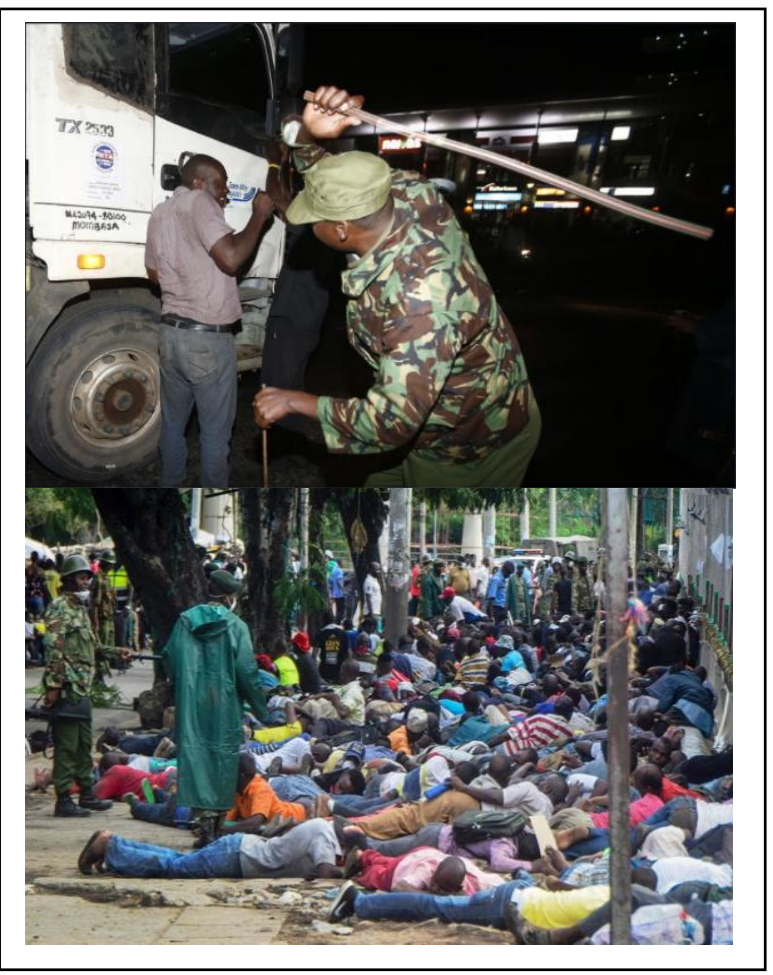

Figure 2: Police actions during the enforcement of dusk to dawn curfew

\section{E. Mental Health Problems and Trauma}

Loss of livelihoods and confinement that resulted from the imposed containment measures for COVID-19 yielded cases of trauma and mental health problems. The cessation of movement in and out of specific counties, quarantine and the dusk to dawn curfew resulted in isolation, containment and loss of livelihoods which in turn caused loneliness, fear, anger and stress from lack of basic needs, particularly among the low-income citizens. According to Infotrack surveys, Covid-19 had caused worry and anxiety to about $75 \%$ of Kenyans.

Regular media interviews with health experts revealed the emergence of suicides and mental health problems associated with COVID-19 impacts. The stigma around the disease posed psychological distress not only to those who had recovered from COVID-19 and their families but also to some healthcare and frontline workers. As a result of family-related frustrations, a young woman killed her four children while a man killed his wife and son in June 2020. A policewoman shot and injured her husband on the allegation of him giving their house help US\$ 0.5 without her knowledge.

\section{F. Teenage pregnancy}

The COVID-19 containment measures that led to the closing of schools, "stay home" directive and restricting movement exposed girl to sexual violence. For instance, the restricted movement somehow hindered accessing sexual and reproductive health and rights (SRHR) information and services. In some hospitals, most of the health workers were reassigned to the COVID-19 crisis. The survey established that most people refrained from going to the hospital in fear of contracting COVID-19 and also increased transport costs to health facilities. The "stay home" directive, which caused the loss of livelihoods particularly in low-income households, forced some children to engage in income-generating activities to support their families. Where schools provided meals and sanitary towels, their closure brought to an end the provisions. These factors singularly or combined increased the vulnerability of young girls to transactional sex to meet their essential needs and also support their families. Although the available March to May data from a government health information system shows no increase in teenage pregnancy compared to the same period in 2019, numerous several cases of teenage pregnancies emanating from defilement by close family members and friends have been reported. During the pandemic period (March to May), about 200 girls aged 14 years and below sought for prenatal services in Machakos County.

\section{THE FLIPSIDE OF COVID-19}

Globally, the COVID-19 pandemic has led to miseries. Whereas this is true, it has opened up opportunities in Kenya that could have otherwise not be exploited. This section highlights the opportunities created by COVID-19.

\section{A. Innovations}

The COVID-19 crisis presented opportunities for young people to develop new technologies in response to the pandemic. Following a series of innovations ranging from the simple hand washing machine to ventilators by Kenya citizens, the government of Kenya through Konza Technopolis Development Authority (KoTDA) alongside other partners launched the Great Covid-19 Innovation challenge. The goal of the challenge was to harness the collective capability of the technology and innovation sector. In addition, the COVID-19 ICT Advisory Committee invited local ICT innovations in food, transport, livelihoods, health, security and economy sectors. Some of the major innovations that emerged to counter the effects of COVID-19 are:

\section{i. Ventilators}

A ventilator is an appliance for artificial respiration. Thus, it helps a patient breathe. In severe cases of COVID-19, patients require the use of ventilators, which unfortunately are only a handful in 
Kenya. Teams of students from Jomo Kenyatta University of Agriculture and Technology (JKUAT) and Kenyatta University developed ventilators (Figure 3). The ventilators largely used locally available materials and would run continuously on a 12voltage battery, electricity or solar. Kenyatta university had a capacity of producing 50 ventilators a week at a cost of KSh 500,000 (US\$ 5000) each.

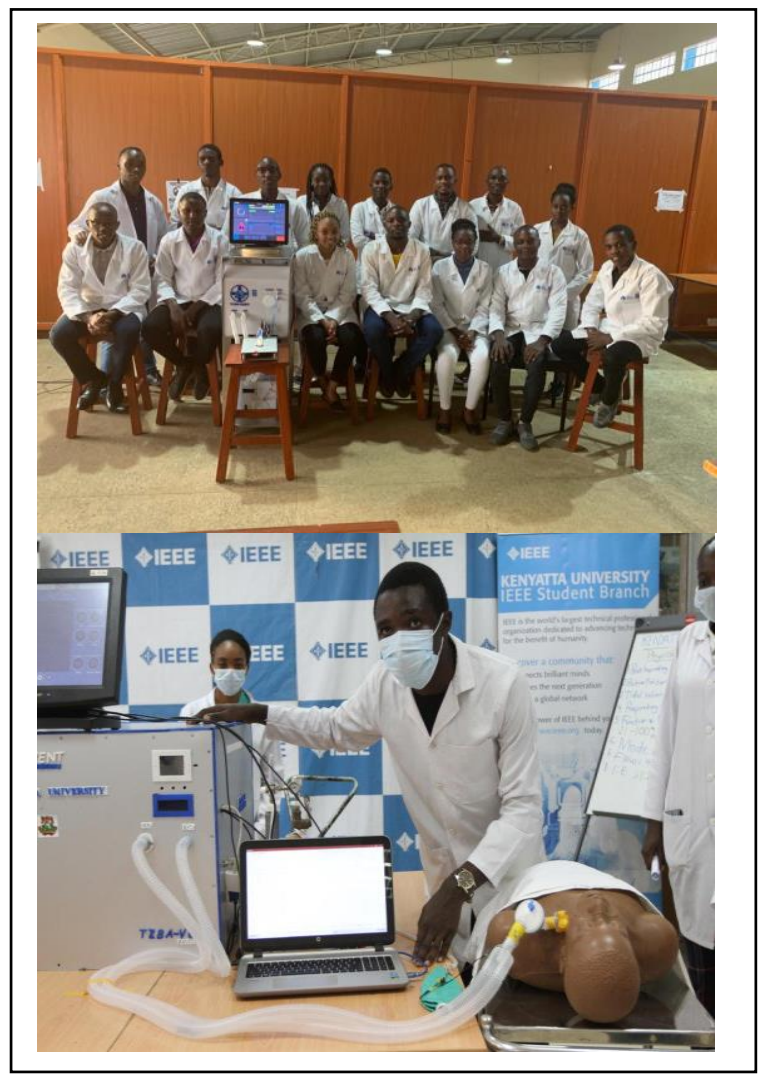

Figure 3: A team of students from Kenyatta University with their locally made ventilator dubbed as Tiba Vent.

\section{ii. COVID-19 Testing kits}

The Kenya Medical Research Institute (KEMRI) developed automated modern testing kits that can test up to 35000 samples in 24 hours. The testing kits have been in use in government testing centres, including KEMRI centres in Busia, Kisumu and Kilifi. Also, KEMRI developed the Point of Contact Rapid Test (PoCT).

\section{iii. Contact Tracing Apps and Web-Based Digital Platform for COVID-19}

People in close contact with someone infected with COVID -19 are not only at higher risk of getting infected but also have the potential for infecting others. Through contact tracing, persons in close contact with those infected are identified, assessed and managed to prevent onward transmission. The Kenya government embraced this strategy of combating the spread of COVID-19 sparking innovation of Apps. A team of three students from JKUAT developed Contact Tracing and Case Management App. The App helps in identifying who, where, and when a person gets into contact with a Covid-19 positive person. Besides, the App includes triaging and case management functions hence reducing cumbersome manual records.

The need to establish the infection trend led to the development of a web-based digital platform that predicts COVID-19 infection trends in Kenya. The platform provides important and diverse data that is crucial in predicting COVID-19 infection trends in Kenya.

\section{iv. Hand Washing Machines}

The call for handwashing as the cheapest and safest way of sanitizing saw an emergence of manual and automated handwashing machines (Figure 4). Innovators used wood, scrap metals and plastic containers. A team of students from Pan African University invented an Automatic Solar Powered Hand Washing Machine that is equipped with a sensor that detects every step when one wants to wash his hands. The machine senses movement of hands closer to the two fitted taps and within a second dispenses soap. For 15 seconds a person will be allowed to scrub his hands and within the next 15 seconds, water flows for rinsing of hands after which it would automatically switch off.

\section{v. Personal Protective Equipment (PPE)}

The rise in PPEs demand and its short supply from the exporters, several companies started making them not only for local consumption but also for export. The Democratic Republic of Congo (DRC) benefited from the PPEs produced in Kenya. Similarly, the demand for face masks led to its production by the Kitui County Textile Centre (KICOTEC) and Eldoret-based Rivatex started producing face masks. KICOTEC produced up to 30,000 pieces of masks day. Hand wash and alcohol-based sanitizers were also produced locally by Jomo Kenyatta University of Agricultural Technology (JKUAT) and other private companies and individuals.

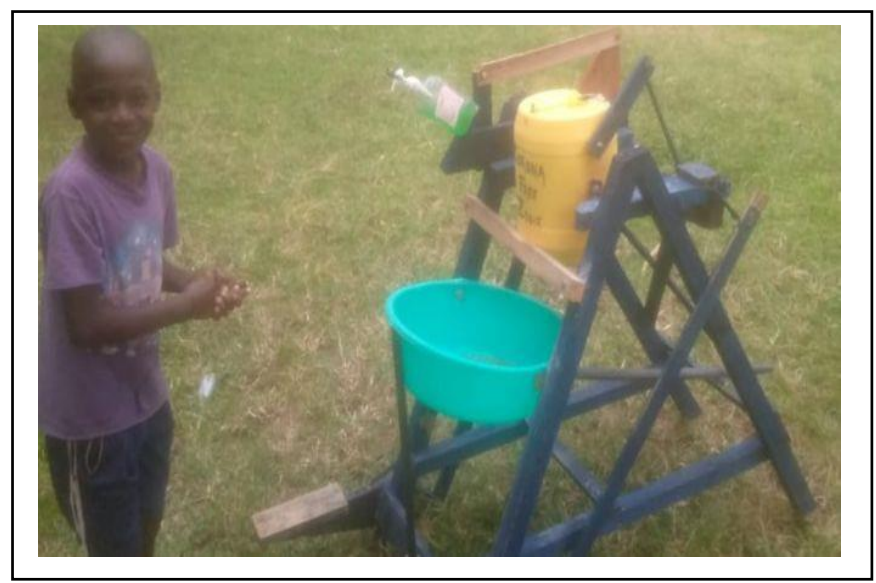

Figure 4: A manual hand washing machine invention by a schoolboy

\section{B. Improved Hospital Facilities}

Although the inpatient bed density remains low at 14 beds per 10,000 people in Kenya against the average of 27, the measure taken to curb the spread of COVID-19 enhanced health infrastructure. The unpredictability of the health impacts COVID- 
19 pushed the national government to fund county governments to improve health facilities in the respective counties. In response to COVID-19, the county governments were allocated US\$ 500 million as conditional grants to improve their health infrastructures. Also, the national government had allocated US\$ 10 million for recruiting additional 6,000 health workers. Each county was required to have a minimum of 300 beds each to COVID-19 isolation facilities. By implementing this directive, the bed capacities in health facilities will improve substantially. With enhanced bed capacity, the pressure on bed space for the patients with non-communicable diseases like diabetes, hypertension and cancer will be eased. Besides, the improved infrastructure will support core universal health interventions and combating malaria, TB and HIV/AIDS. A statement by the chairperson of Council of Governors (COG) indicated that by end of June 2020, 36 counties had a total of 343 beds (Figure 5) while 28 counties had acquired a total of 337 ventilators.

(a)

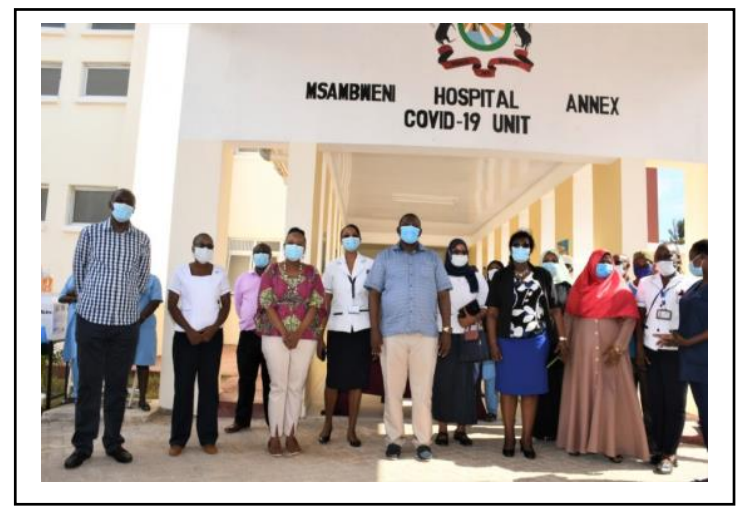

(b)

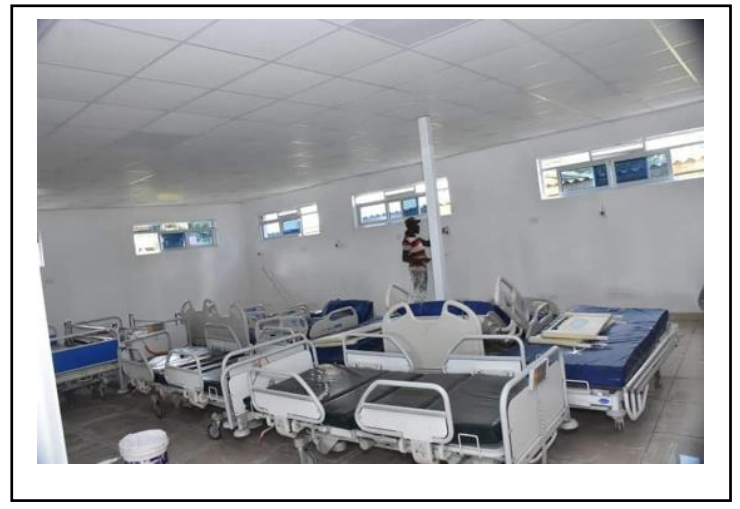

Figure 5: (a) An Improved Msambweni hospital in Kwale County and (b) the newly installed 35 ICU bed in Murang'a

\section{Diversification of Livelihoods}

The "stay home" directive disrupted the economy of the country with the majority of the employees in private enterprises either losing their jobs or having pay cuts. The government ordered people to work from home except for essential services. Thus, the majority of people were required to stay at home. Further disruptions were occasioned by the cessation of movement in and out of Nairobi Metropolitan area which hosts the capital city, Mombasa and Mandera counties. The majority of the people who lost their jobs and those who were still in employment but staying at home sought alternative sources of livelihoods. As a consequence, the car boot vegetable business boomed soon after the country partial lockdown (Figure 6). Majority of the people who engaged in car boot business were initially the taxi operators and those who lost their jobs or whose line of trade was affected by measures put in place to contain the disease. As an alternative source of livelihood, the survey revealed that some of the people intend to continue with the vegetable business even after the pandemic. However, some entrepreneurs started businesses such as making hand sanitizers and face masks after identifying a gap and chose to cash in. Although the quality of the hand sanitizers and face masks was not guaranteed, many Kenyans used them because of their accessibility and affordability.

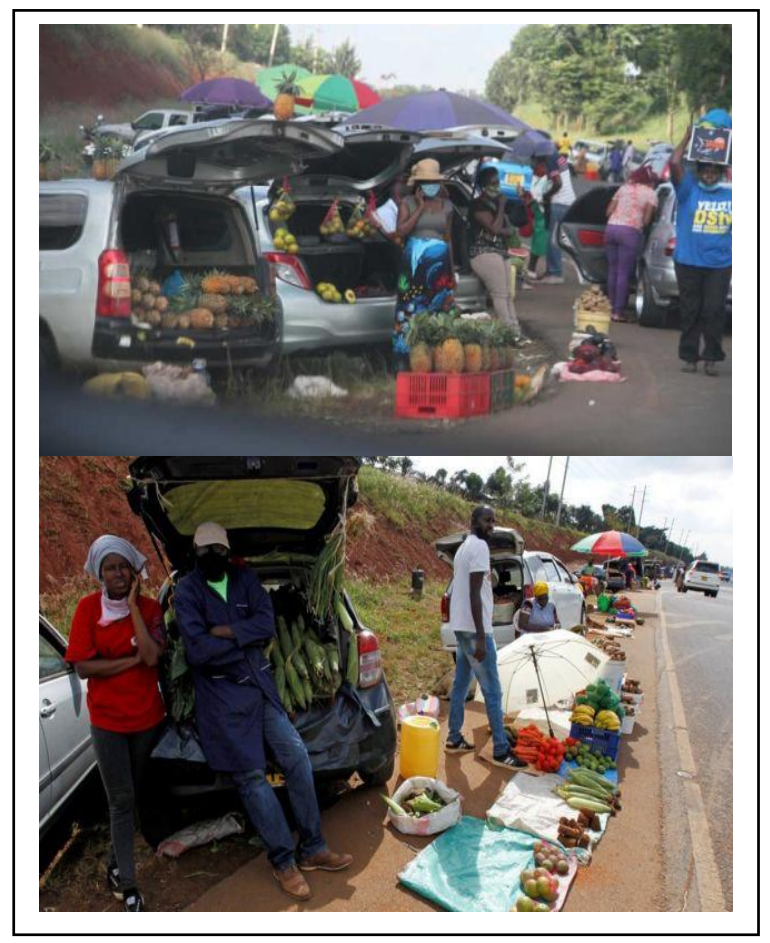

Figure 6: Car boot vegetable business along the roads in residential areas

The long boring days occasioned by the "stay home" government orders for people who were still in employment provoked business thoughts. Key among the ideas actualized were the establishment of general merchant shops and agribusinesses. Mr Chore, a lecturer at Garissa University had this to say.

"Staying at home is very boring especially when you have nothing to do. I am just in the house without any work. What could happen if the university decides not to pay us? My God, I would be a beggar. This COVID-19 has taught me a big lesson. I need to diversify my livelihood source. I have started poultry and dairy farming. I have over 300 birds and 40 calves on my farm."

Prof. Huho who is an Associate Professor of Geography at Garissa University started greenhouse farming after a month of staying at home (Figure 7). 


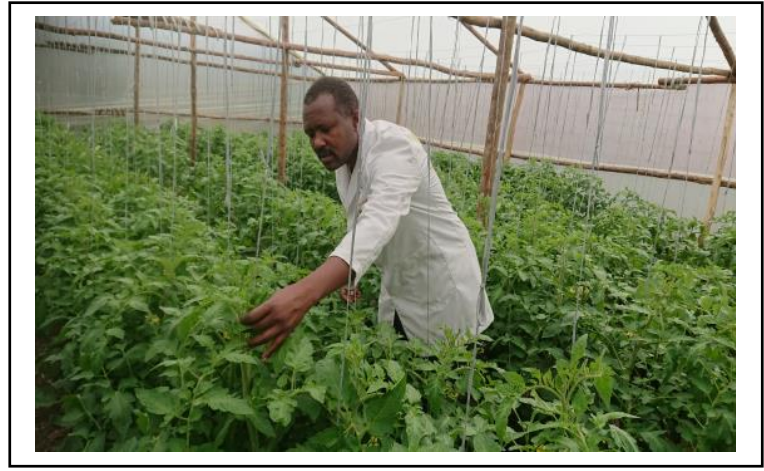

Figure 7: Prof Huho tending his tomatoes in a newly established greenhouse during the COVID-19 "stay home" break

\section{Improved Hygiene}

The call for handwashing and sanitizing was largely embraced. Washing points were located in strategic locations in public places (Figure 8). Regular handwashing has become the norm. Whereas the culture of shaking hands for greetings may not disappear completely, a shift from the practice is expected henceforth. A quick telephone survey for this study revealed that $52 \%$ of the responded were against the usual way of handshaking after COVID-19. They argued, where shaking hands is inevitable, that they will prefer to use a fist bump or high five. However, the other $54 \%$ stated that handshaking is African and they will continue after containment of COVID-19. Studies indicate avoidance of handshaking greatly reduce the spread of bacteria between people. The probability of transferring bacterial through normal handshake reduces by half compared to a high five and even lower when fist bump is used.

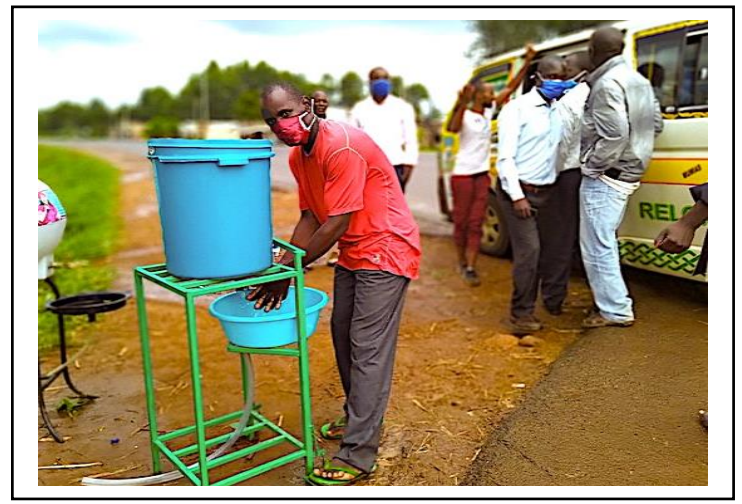

Figure 8: Hand washing points in public places in Kenya

\section{E. Adoption of ICT}

With all educational institutions closed down in mid-March 2020, institutions at all levels were required to looking for alternative ways and means of ensuring that learning continues remotely. The ministry of education partnered with other stakeholders to ensure learning was going on. This was through TV and radio. In universities and high-cost private institutions (primary and secondary), online learning pedagogy was adopted. The online teaching has opened up opportunities not only for content developers but also for the establishment of institutions in remote areas where learners can be taught online. Meetings were held remotely cutting the cost of travel and other logistics associated with meetings. Again, enhanced use of ICT has also been witnessed in the marketing sector than it has ever been in Kenya. In mid-March 2020, a digital directory for locally manufactured goods was launched by the Kenya Association of Manufacturers to help customers shop online via cashless platforms.

\section{F. Tight Family Ties}

Whereas the "stay home" directive by the government has seen the upsurge in domestic violence, on one hand, it has also led to even stronger bonds between families. The survey established that the $7 \mathrm{pm}$ to 5 am curfew imposed in Kenya forced all family members to be in the house by early. Although men somehow felt oppressed by the curfew hours majority of the married women indicated that they were happy to have their husbands get home early. Some of the parents turned the "stay home" directive into opportunity by sparing time to and developing a more intimate relationship with their families. It was evident that the Covid-19 pandemic had reshaped relationships among spouses and children. Most families had become even closer than they were before with stronger bonds since parents and kids had more time together. Mr Mwangi, a residence in Machakos County, states the following.

"This COVID-19 has made me realize that I had unknowingly neglected my family. I never had quality time my children since most of the times I will get home not earlier than $8 \mathrm{pm}$. Soon after they will go to sleep. Besides, I never had time to look at their school homework or what they are taught at school which am currently doing. I am also assisting my wife with some duties at home. My family is now united than before"

\section{G. Financial Relief}

COVID-19 presented two sides of the financial wellbeing of the citizens. Whereas some people faced financial hardships as discussed earlier, some enjoyed full or partial tax relief from the government for three months. The part of the salary that could have otherwise consumed by the tax was spared and used for other purposes. Other financial relief included the suspension of bank loans, suspension of blacklisting in Credit Reference Bureau (CRB blacklists loan defaulters) and some tenants had their house rent waived or reduced. The boda boda riders (motorcycle taxis), particularly those who sneaked people past the erected road barriers that prevented movement in and out of the counties of Nairobi, Mombasa and Mandera, indicated that the business was rewarding. They made up to US\$30 per day against the usual US\$ $10-15$ without the barriers.

\section{LESSONS LEARNT}

COVID-19 has undoubtedly taught people several lessons. Among the major lessons learnt were:

a) Never rely on a single source of income. After the job losses, people with one source of income were the most affected since they had nothing to cushion themselves against.

b) Family comes first. Under the guise of working, some parents had absconded their families. where jobs were lost, the truant parents went back to their families for material and emotional support.

c) The important role of teachers in society. The closure of schools has since forced parents to stay with their children at 
home. This study established that most parents preferred when their children were in schools where teachers guide them on academic work and discipline. Some respondents argued that teachers, particularly at elementary levels, ought to be the highest-paid civil servants in Kenya.

d) Potential adoption of flexible working conditions. The "work from home" directive by the government has seen enhance the use of technology to achieve while at home what could have otherwise been in the office. Working from home has not only minimized transport costs incurred by employees but has also saved on office overhead expenses and also office spaces.

e) Potential adoption of online learning. Although online learning is not a new phenomenon in Kenya, its uptake by many learning institutions (basic education to tertiary education levels) during the COVID-19 crisis was an indicator that of the possible increase of online learning centres.

f) With good political will, Kenya can industrialize earlier than anticipated. The innovation such as the development of ventilators and test kits by university students and other people was an indicator on the level of technological development capacity available in Kenya. It only requires adequate financing and establishment of innovation hubs.

\section{REFERENCES}

[1] WHO (2020) Coronavirus. Available online at: https://www.who.int/healthtopics/coronavirus\#tab=tab_1

[2] Worldometer (2020) Coronavirus Cases. Available online at: https://www.worldometers.info/coronavirus/ [accessed 8/7/2020]

[3] OCHA (2020) KENYA: Situation Report. Available online at: https://reports.unocha.org/en/country/kenya [accessed 14/7/2020]

[4] Mahtani, S. (2020) What must governments do to reduce gender-based violence during the COVID-19 pandemic? Available online at: https://www.africaportal.org/features/what-must-governments-do-reducegender-based-violence-during-pandemic/ [accessed on 14/7/2020]

[5] Chuku, C., Mukasa, A. and Yenice, Y. (2020) Putting women and girls' safety first in Africa's response to COVID-19. Available online at: https://www.brookings.edu/blog/africa-in-focus/2020/05/08/puttingwomen-and-girls-safety-first-in-africas-response-to-covid-19/ [accessed 14/7/2020]

[6] Owino, E. (2020) Socioeconomic impacts of Covid-19 in Kenya. Available onlin at: https://devinit.org/resources/socioeconomic-impacts-covid-19kenya/ [accessed 14/7/2020]

\section{AUTHORS}

Correspondence Author - Julius M. Huho, Associate Professor of Geography, Garissa University Kenya.jmhuho@gamil.com, $+254722218668$ 